\title{
San Martín y Bolívar: Los debates entre los legionarios ingleses e irlandeses sobre los méritos de los libertadores
}

\section{San Martin and Bolivar: The debates between the English and Irish legionaries on the merits of the liberators}

Celia Wu Brading

\section{Resumen}

El artículo rastrea los orígenes del debate proveniente de un grupo selecto de legionarios ingleses e irlandeses, especialmente de Sir Belford Hinton Wilson y del General William Miller, que militaron con San Martín y Bolívar. También da a conocer las opiniones divergentes sostenidas sobre ambos personajes por sus partidarios ingleses e irlandeses, que reflejan las opiniones y los prejuicios de los generales, ideólogos y políticos hispanoamericanos de la época de la independencia, que se mantiene hasta nuestros días al comparar los contrastes entre la figura y obra de los dos grandes libertadores.

Palabras clave: José de San Martín, Simón Bolívar, Belford Hinton Wilson, William Miller

\section{Abstract}

The article traces the origins of the debate from a select group of English and Irish legionaries, especially Sir Belford Hinton Wilson and General William Miller, who served 
San Martín y Bolívar: Los debates entre los legionarios ingleses e irlandeses sobre los méritos de los libertadores

San Martín and Bolívar. It also reveals the divergent opinions held about both characters by their English and Irish supporters, which reflect the opinions and prejudices of generals, ideologues and Latin American politicians of the independence period, which is sustained to this day when comparing the contrasts between the personalities and accomplishments of the two great liberators.

Key words: José de San Martín, Simón Bolívar, Belford Hinton Wilson, William Miller

\section{Introducción}

Los cultos surgidos alrededor de José de San Martín y Simón Bolívar en América del Sur fueron, con algunas excepciones, estrictamente de carácter territorial. En Venezuela, Colombia y Ecuador se veneró y se elevó a Bolívar a los altares; en Argentina, Perú, Bolivia y Chile se aclamó a San Martín como libertador y se estableció entre ellos cierta hermandad sanmartiniana.

En la famosa entrevista de Guayaquil en 1822, San Martín tomó la decisión de retirarse de la escena y dejar a Bolívar asumir la gloria de completar la independencia de América del Sur en el Perú. No hubo testigos de esa reunión y ninguno de los protagonistas divulgó por completo la conversación sostenida, aunque fue evidente el desagrado mutuo. El diálogo quedó rodeado de misterio y mitos, y quienes aportaron las versiones de la reunión fueron los cercanos a los interlocutores, versiones que desde el comienzo se caracterizaron por su arbitrariedad y, al mismo tiempo, estuvieron teńidas de alabanzas hacia uno y desdén hacia el otro. La entrevista de Guayaquil captó la imaginación de literatos sudamericanos como Ricardo Palma, quien se refirió a ella en sus Tradiciones 
peruanas, y Jorge Luis Borges, que la usó como fuente y nos legó Guayaquil, un cuento delicioso.

Los primeros en abrir el debate en la controversia sobre los respectivos méritos de San Martín y Bolívar fueron los historiadores de la emancipación. En 1883, durante el gobierno de Antonio Guzmán Blanco, salieron a la luz en Caracas las Memorias de Daniel O'Leary, una narrativa de la carrera de Bolívar en dos tomos, acompañados de 29 volúmenes de documentos y papeles personales del Libertador. Pero esas Memorias, escritas en los años cuarenta, reflejaban en cierta medida una voz del pasado, aunque en parte hayan sido traducidas y publicadas por el hijo del autor, Simón O'Leary. La decisión del presidente Guzmán Blanco de publicarlas obedeció a un momento político trascendental; Venezuela gozaba en los ochenta de prosperidad económica y estabilidad política, después de años de caos e inseguridad. El mandatario, determinado a reafirmar la regeneración del país y también su propia popularidad, recurrió a invocar una figura heroica que daría a la nación su sentido de identidad. Nació así la glorificación de Bolívar, mito que fue difundido por políticos y escritores.

Daniel O’Leary (1801-1854), un irlandés que consiguió ser edecán de Bolívar a la edad de 18 años, llegó a Venezuela en 1817 como legionario y en 1820, después de combatir en Boyacá, ingresó al círculo de poder del Libertador. En sus Memorias describe la vida de un héroe inmaculado, de un Napoleón americano fiel a sus principios republicanos, que se negó a ser coronado rey o emperador a pesar de que tenía predilección por un gobierno central y fuerte. Asimismo, exalta las virtudes y los logros de Bolívar, y denigra sin reserva a sus contrarios, ya fuesen Páez, Santander, Rivadavia o San Martín. Al relatar la entrevista de Guayaquil, O'Leary (1984) compara a los dos libertadores con la intención deliberada de irritar a todos, en particular, a 
San Martín y Bolívar: Los debates entre los legionarios ingleses e irlandeses sobre los méritos de los libertadores

los más arrebatados entre los bolivarianos. Los capta en los siguientes términos:

Franco, ingenuo, ardiente en sus amistades y generoso con sus enemigos era Bolívar; San Martín, frío, disimulado e incapaz de perdonar las injurias o de hacer un beneficio que no redundase en su provecho. El argentino, recompensado por sus servicios al Perú, abandonó su causa; el venezolano, proscrito por sus compatriotas, volvió a Colombia y les dio libertad. Hereda éste cuantiosos bienes de fortuna y muere casi en la indigencia. Nace y se cría aquél en la pobreza y adquiere una fortuna. San Martín acepta el título de Protector del Perú; Bolívar rechaza la corona que se le ofrece en Colombia.

Y como si eso no fuese suficiente, O'Leary también alaba la Constitución que Bolívar dio a la república que tomó su nombre, como un antídoto necesario a la anarquía política que dominaba entonces las provincias del Río de la Plata. Ese desdén y rechazo de la contribución argentina a la liberación de América del Sur dio pie a que Bartolomé Mitre escribiera su Historia de San Martín y de la emancipación sudamericana, obra inmensa y magistral sobre la lucha por la independencia de las colonias españolas. Se publicó en 1887 y una segunda edición salió en 1890, compuesta de cuatro volúmenes lujosamente ilustrados. Lo que el estudio de Mitre deja traslucir es la reafirmación de la confianza y el sentido de suficiencia de Argentina, fundamentada en el logro de su unidad nacional y la expansión destacada de su economía de exportación. La versión de los sucesos por Mitre estaba destinada a convertirse en la fuente principal del estudio de la historia del movimiento de independencia en todos los países que reconocieron a San Martín como su libertador. Lo que hizo Mitre fue ensalzar al héroe argentino como el fundador de "una constelación" de repúblicas, cada una de ellas asentada sobre una nacionalidad histórica y separada. En contraste, repudió a Bolívar como un "genio desequilibrado". Concluyó que "en el orden definitivo de las cosas, el triunfo de los principios 
fundamentales de la revolución sudamericana corresponde a San Martín, aunque la gloria de Bolívar es mayor" (t. 2, p. 985). En todo esto, Mitre desplegó las cualidades de un verdadero historiador y al admitir las faltas de San Martín, lo que buscó fue convencer a sus lectores en cuanto a la exactitud de su juicio de interpretación. Por otro lado, la narrativa de Mitre se prestó a una disección implacable por parte del ensayista venezolano Rufino Blanco Fombona.

En medio del ruido y la furia que produjo ese gran debate entre historiadores polemistas argentinos y venezolanos sobre el mérito respectivo de los dos libertadores, la discusión se inició en parte por el grupo selecto de legionarios ingleses e irlandeses que militaron con San Martín y Bolívar. Este artículo no trata de analizar la obra de Mitre ni la de sus opositores, sino más bien rastrear los orígenes de un debate proveniente de ese círculo notable de legionarios británicos. Así mismo, da a conocer las opiniones divergentes sostenidas sobre estos dos personajes por sus partidarios británicos.

El hallazgo de una colección de cartas en The John Carter Brown Library escritas por Belford Hinton Wilson, edecán de Bolívar, a su compatriota el general William Miller, aporta nuevas revelaciones en cuanto a sus reacciones. La correspondencia, redactada a menudo en términos severos y violentos, deja ver la devoción extraordinaria que Bolívar despertó entre sus seguidores más cercanos y al mismo tiempo pone de manifiesto el recelo elocuente que suscitaban esos proyectos entre los allegados a San Martín.

\section{Belford Hinton Wilson}

Un pasaje que ilustra las estrechas relaciones que mantenían entre sí el grupo de ingleses e irlandeses es la invitación que el coronel Francis Burdett O'Connor (1791-1871) extendió al general William Miller y al capitán Belford Hinton Wilson para compartir una botella de vino en vísperas de la batalla 
San Martín y Bolívar: Los debates entre los legionarios ingleses e irlandeses sobre los méritos de los libertadores

de Junín (de no haber sido destacado Daniel O’Leary a una misión en Chile, no cabe duda que se les hubiera sumado), mientras el Libertador dormía en un lugar contiguo, separado solo por una pared (O'Connor, 1915). Tres de esos cuatro hombres, O'Leary, O'Connor y Miller, describieron en sus memorias sus campañas en el Perú y trazaron semblanzas de Bolívar. No era la nacionalidad lo que los dividía, sino el origen de su aventura americana. O'Connor, O'Leary y Wilson se habían enrolado al servicio de Bolívar, y los dos irlandeses habían luchado en Venezuela; en cambio, Miller se sumó a las fuerzas de San Martín en Chile, combatió por la independencia de ese país y luego acompañó al argentino en la invasión del Perú. Por último, en los cuarenta, O’Leary se desempeñó como chargéd'affaires de su majestad en Bogotá, Wilson lo fue en Caracas y Miller en las islas Sandwich (más adelante conocidas como Hawái al integrarse al territorio estadounidense). En contraste, O’Connor pasó el resto de su vida en Tarija, se casó con una boliviana y se dedicó a la agricultura.

En Generales y diplomáticos de Gran Bretaña y el Perú, 18201840 (1993, cap. IV) perfilé la carrera de Belford Hinton Wilson (1804-1858) como edecán de Bolívar y ministro británico en los treinta en el Perú. Para mí, entonces ya era clara su gran devoción a Bolívar incluso después de su muerte; pude ofrecer una descripción general de cómo Wilson vio los muchos logros del Libertador. Las cartas escritas por Wilson a William Miller confirman su profundo apego a Bolívar. Para entender su importancia, hay que tener en cuenta que Belford era hijo de sir Robert Wilson, general y miembro del Parlamento, quien mantenía correspondencia con Bolívar, apoyó el movimiento de independencia y consideró participar en él. Finalmente, envió a su edecán James Charles a las fuerzas de San Martín y a su hijo a las filas del héroe caraqueño (Wu Brading, 2004). Una vez que Belford se incorporó a las tropas de Bolívar, a la edad de 18 años, no tardó en 
llegar a ser uno de los más fieles del grupo íntimo del adalid, quien observó: "El joven Wilson se conduce cada día más a mi satisfacción; su respeto y su amor al padre lo ligan de tal modo a los sentimientos que me profesa que algunas veces me parece tener en él a un hijo" (O'Leary (1888), carta de Robert Wilson a Bolívar, 2 de julio de 1822). El apego fue recíproco: Wilson veía en Bolívar a un padre, lo cual resulta evidente en su correspondencia.

Wilson nació en 1804 en Londres, no en Irlanda como afirma Gabriel García Márquez en su novela El general en su laberinto, en la que aparece cerca del Libertador. Estudió en Westminster y en la academia militar de Sandhurst. En 1822 cruzó el Atlántico; portaba cartas de recomendación al vicepresidente Santander en Colombia y a Simón Bolívar, en las que su padre pedía que fuese integrado en el ejército de Colombia. Sobre su vástago, escribió: "Educado en la escuela militar, tiene ya el conocimiento elemental del oficio, y junto a una educación esmerada ha gozado de ventajas fortuitas que le han hecho adelantar su espíritu más que su edad" (Bolívar, 1950, v. 3, pp. 529-531). Al llegar a Bogotá, Wilson recibió el grado de subteniente y fue incluido en el cuerpo de edecanes; de inmediato se dirigió al Perú para reunirse con Bolívar, con quien se encontró en agosto de 1824.

Wilson fue recibido cálidamente por el Libertador, quien lo ascendió a capitán, y en tal capacidad participó en la batalla de Junín. En 1825. lo acompañó en su recorrido triunfal a lo largo de la región andina, desde Arequipa a Cuzco, Potosí y Chuquisaca. Para entonces, ya formaba parte del círculo íntimo de Bolívar, donde figuraban también dos irlandeses, Daniel O'Leary y William Ferguson. En mayo de 1826 el líder caraqueño confió a Wilson la encomienda de entregar en persona la Constitución boliviana. Para esa misión, que cumplió con diligencia y orgullo con el nombre pintoresco de Viracocha, cabalgó 19 días por casi tres mil kilómetros de 
San Martín y Bolívar: Los debates entre los legionarios ingleses e irlandeses sobre los méritos de los libertadores

territorio accidentado. En recompensa por ese acto de heroísmo, el general Antonio de Sucre y el Congreso Nacional de la nueva república acordaron promoverlo al rango de coronel, un honor para un joven de 22 años (Wu Brading,1993, p. 100). En sus Memorias, publicadas en 1828, William Miller (1929) subraya: "El coronel Wilson es un gallardo joven que ofrece las mayores esperanzas y heredero de los talentos de su padre; sus modales eran sumamente apreciados, siempre buscaba oportunidades para ser útil a sus paisanos cuando, empleando su influencia con el Libertador, podía ayudarlos de algún modo. Pocos gozaban de la confianza de Bolívar en mayor grado que el coronel Wilson" (v. 2, pp. 297-299).

En 1828 el joven edecán retornó a Inglaterra con la esperanza de conseguir un puesto diplomático; Bolívar le concedió licencia y le permitió seguir usando el uniforme del ejército colombiano. Para entonces, las relaciones entre el Perú y Colombia se habían deteriorado y amenazaba la guerra entre los dos países. Para Wilson, alejarse del Libertador fue muy doloroso y en su viaje de regreso iba dispuesto a defender su buen nombre. A su paso por Washington, D. C. conoció al presidente Andrew Jackson y al senador Henry Clay, y trató en esos círculos políticos de salvaguardar la reputación de Bolívar, de quien se había dicho que era un déspota que había intentado extender su influencia hacia el norte, sometiendo la entera cadena de repúblicas a la hegemonía británica. Sin lugar a dudas, ese era un eco del Congreso Panamericano que el Libertador había convocado en Panamá. Para entonces, Francisco de Paula Santander y Benjamin Constant en Europa lo habían atacado ferozmente. Ante ello, Wilson decidió publicar un artículo en una revista de Baltimore, en el que condena la invasión peruana de Colombia, y en un discurso en el Ateneo de Boston describió a Bolívar como protector y mecenas de las artes y ciencias de América del Sur. Igualmente, en Inglaterra redobló sus esfuerzos por defender a Bolívar en los círculos políticos y en la prensa. Hizo arreglos para 
que se publicasen estudios relativos a Colombia en The Star con el fin de refutar las opiniones desfavorables procedentes de los Estados Unidos. Wilson no descansó en su campaña bolivariana; visitó a comerciantes vinculados con América del Sur y viajó a los pueblos manufactureros del norte con el objeto de incrementar su volumen de intercambios con la región. En esas ocasiones, se esforzaba siempre en defender las ideas y la conducta del Libertador (Wu Brading, 1993, p, 108).

Las esperanzas de Wilson de obtener un puesto en el gobierno de su país no se materializaron y no le quedó más opción que regresar a Sudamérica. Cuando volvió al lado de Bolívar en enero de 1830, encontró que su estrella política se había apagado y que era un giro irreversible. En el curso de ese año tuvo lugar la desintegración de Colombia en tres estados independientes y el Libertador renunció a la presidencia. Eran circunstancias difíciles y a Wilson le correspondió acompañar a Bolívar en esa nueva etapa de su vida privada y permaneció a su lado durante la enfermedad que presagiaba el trágico final. Wilson estuvo presente en la muerte del Libertador en Santa Marta y fue testigo de sus últimas instrucciones testamentarias. En un legado redactado en diciembre de 1830, Bolívar solicitaba a sus albaceas "que den las gracias al general Robert Wilson por el buen comportamiento de su hijo, el coronel Belford Hinton Wilson, que tan fielmente me ha acompañado hasta los últimos momentos de mi vida" (Bolívar, 1950, v. 3, pp. 529-531).

\section{William Miller}

$\mathrm{Al}$ estudiar las cartas de Wilson, que suman un total de ocho, escritas entre 1828 y 1856 desde Colombia, Londres, Madeira y Perú, lo que hallamos no es una descripción o un panegírico del héroe venezolano, sino más bien un ataque demoledor contra el general Miller por sus críticas al Liber- 
San Martín y Bolívar: Los debates entre los legionarios ingleses e irlandeses sobre los méritos de los libertadores

tador. En su primera misiva, Wilson advierte a Miller: "Debo suplicarte que de aquí en adelante tengas presente que estimo al general Bolívar como a un padre, pues como tal se comportó conmigo" (Carta de Wilson al general William Miller, Cartagena, 18 de setiembre de 1828). ${ }^{1} \mathrm{El}$ tono irascible de Wilson se debe al nivel de recriminación y descrédito contra Bolívar que percibe en las cartas de Miller (de las cuales solo una está en la colección y otras tres se hallan en los papeles de O'Leary). Wilson también acusa a Miller de "orgullo herido", y cree "firmemente que ni la enemistad del general Miller, ni los celos mezquinos de los jefes o la ingratitud de los traidores nativos podrán jamás disminuir en un ápice la gloria del Libertador de Colombia y Perú". Lo incrimina también por permitir que sus pasiones cieguen sus juicios. Lo único que acepta de las muchas denuncias de su compañero de armas es que a él y a O'Leary se les llame the firebrands, los agitadores por la causa del Libertador.

La razón de tan encendidas y hasta implacables opiniones de Wilson era la postura que Miller había asumido en defensa de los generales peruanos en la declaración de la guerra del Perú a Colombia en 1828-1829. Wilson los condena y lamenta la imbecilidad, la insensatez y la ingratitud de los peruanos. Y en cuanto a "las calumnias del despecho malicioso" contra Bolívar, le dice a Miller: "la actual situación de América del Sur es su mejor defensa" (Carta de Wilson al general William Miller, Madeira, 21 noviembre de 1829). Respecto del prestigio del Libertador, Wilson no ahorra palabras para recriminar a su corresponsal: "censuras implacablemente el carácter de Bolívar y llamas viles sicofantes a quienes estaban a su alrededor. La reputación del Libertador es muy cara para muchos. No menos lo es nuestro honor. Defenderemos ambos". ${ }^{2}$ Tampoco escatima calificativos al aludir a la dureza

1 Sir Belford Wilson Letters 1828-1856. The John Carter Brown Library.

2 Las tres cartas de Miller se encuentran en O’Leary (1920, t. 1). 
y severidad de sus juicios respecto de otros personajes: "Ni siquiera tu protector y favorito San Martín escapa del todo al látigo de tu ira" (Wilson a Miller, 21 de noviembre de 1829. Miller a Wilson, 25 de febrero de 1830). A pesar de esa crítica feroz y descarnada, Wilson reitera a Miller su amistad y su respeto (aunque no puede resistir referirse a él como "el poeta laureado de los generales peruanos"). La razón no es solo que Miller había tratado bien a Wilson en el Perú, sino que también le había dedicado un comentario honroso en sus Memorias.

Si las Memorias de Miller despertaron en Wilson esa respuesta violenta, enfurecieron asimismo a otro de sus compatriotas, al coronel John O'Brien (1786-1861), natural de Irlanda, que también había luchado heroicamente al lado de San Martín y Bolívar. Durante su desempeño como gobernador provisional del Cuzco en 1835 y cuando el presidente Luis José Orbegoso visitaba la ciudad imperial, O’Brien manifestó su airada protesta contra las Memorias en un "auto de fe" que tuvo lugar el 20 de enero, en nombre suyo y en el de los ausentes, por lo "poco exacto de las narraciones de los hechos". Las quemó en un brasero en la plaza del Regocijo. El autor ejercía entonces el cargo de comandante general de las armas de la República en el Cuzco, Puno y Arequipa y se hallaba en la ciudad imperial, donde se había celebrado un mes antes el décimo aniversario de la batalla de Ayacucho (Denegri Luna, 1955).

En Inglaterra, las Memorias fueron ampliamente elogiadas en numerosas reseñas, hasta el punto que a Miller se le vio como un "héroe joven" y fue honrado en Canterbury, su ciudad natal. Mas, a pesar de su importancia, jamás han recibido un escrutinio propiamente histórico, en parte porque los capítulos dedicados a las hazañas de Miller están relatados de una manera tan novelesca que se asemejan a las aventuras románticas de la época y luego fueron empleadas como tales 
San Martín y Bolívar: Los debates entre los legionarios ingleses e irlandeses sobre los méritos de los libertadores

por distintos narradores, como G. A. Henty ${ }^{3}$ en sus historias para nińos y adolescentes.

Los dos volúmenes de las Memorias abarcan un amplísimo territorio; no resulta fácil desentrañar su plan ni su compleja estructura. Para comenzar, fueron escritas por John Miller, hermano del general, quien echó mano "de la correspondencia personal, los diarios y las anotaciones de mi hermano, el general Miller. Esos documentos ofrecen material abundante para la relación de las operaciones de la guerra de independencia y contienen descripciones y observaciones, incidentes y anécdotas que ilustran acerca del carácter, los usos y las costumbres de la gente”. Uno de los objetivos era "pintar con los colores verdaderos el mérito, valor, constancia y natural benevolencia del paisanaje y la tropa del Perú, Chile y Buenos Aires, que poseen estas buenas cualidades a pesar de tener otros vicios, consecuencia del contagio español y el mal gobierno" (Miller, 1929). Efectivamente, se combinan las hazañas de Miller con la descripción de los habitantes y paisajes para armar el primer relato general en inglés de las guerras de la independencia en Sudamérica. Si las Memorias tuvieron tan sonado impacto fue porque reunían los recuerdos personales con la historia general, y a eso se agrega, como ya se dijo, la descripción de lugares y habitantes. Para complicar más las cosas, un año después aparecieron una segunda edición en inglés con textos ańadidos y una versión castellana traducida por el exiliado español José María Torrijos. ${ }^{4}$

3 George Alfred Henty (1832-1902), novelista y corresponsal de guerra victoriano, conocido por sus historias de aventuras. Entre sus obras están The Treasure of the Incas, Out on the Pampas y With Moore at Corunna.

4 Torrijos fue un general español que se distinguió en la defensa de su país durante la invasión napoleónica. De ideas liberales y perseguido por los absolutistas, se exilió a Inglaterra, donde se ganó la vida como traductor. 
Antes de tratar de entender el contexto, conviene comentar brevemente la extraordinaria carrera de William Miller. Nació en 1795 e ingresó en la artillería británica; sirvió en España y Portugal de 1811 a 1814, formó parte de la expedición para luchar contra George Washington y en Nueva Orleans. Después de la declaración de paz en Europa, se dedicó a la actividad mercantil, lo que no le satisfizo. Viajó entonces a Buenos Aires, se asimiló al ejército de San Martín en Chile con el grado de capitán de artillería y participó en la batalla de Maipú, que terminó con el dominio español en ese país.

En el mismo año participó en la expedición naval de Lord Cochrane para liberar América del Sur y fue nombrado mayor de marina bajo el mando del capitán de corbeta Charles, quien había sido edecán de sir Robert Wilson. Miller acompañó a Cochrane en el asalto del Callao y participó en los ataques a Pisco, Valdivia y Chiloé, donde resultó gravemente herido dos veces. Siguió a San Martín al Perú y fue designado coronel de la legión peruana. En 1823, durante el breve gobierno presidencial de José de la Riva Agüero, fue uno de los cuatro generales de brigada del ejército peruano. Para entonces se había distinguido en varias campañas con cuerpos del ejército relativamente pequeños a lo largo de las costas peruanas, conocidas como Puertos Intermedios. Cuando llegó Bolívar en junio de 1824, lo nombró comandante de la caballería peruana y con ese cargo participó en la batalla de Junín. Más adelante, como uno de los jefes de brigada, actuó en Ayacucho y contribuyó a la victoria. En 1825 era gobernador de Potosí y fue ascendido a general de división (Wu Brading, 2007 y 2019).

Una vez que Bolívar hizo su entrada triunfal a Potosí y recorrió la región andina sur, Miller dejó el Perú y regresó a Inglaterra, donde publicó sus Memorias. No pasó inadvertido que un joven de 30 años tuviese el grado de general; en 1843 fue nombrado cónsul y comisionado en el reino de las islas Sand- 
San Martín y Bolívar: Los debates entre los legionarios ingleses e irlandeses sobre los méritos de los libertadores

wich. En 1859 decidió regresar al Perú y el Congreso le restituyó el grado de mariscal que le había sido concedido por el presidente Luis José de Orbegoso en 1834. Sin embargo, el entonces presidente, el general Ramón Castilla, se lo negó, y tampoco le concedió recobrar su pensión y distinciones. En 1861, Miller escogió morir a bordo de un buque británico en aguas peruanas. La autopsia reveló dos balas, que databan de cuarenta ańos atrás y 23 cicatrices. Irónicamente, se le enterró con los solemnes honores correspondientes a un mariscal del ejército peruano y desde 1916 sus restos descansan en el Panteón de los Héroes junto a los generales peruanos fundadores de la nación (Wu Brading, 2007 y 2019).

\section{Las Memorias de William Miller}

En cuanto a las Memorias, la narrativa de las hazañas de Miller comienza con 132 páginas de descripción del colonialismo espańol, las primeras revueltas entre 1808 y 1810 a lo largo del subcontinente, desde Caracas hasta Buenos Aires, y concluye con la aparición de San Martín y su cruce de los Andes hacia Chile. El listado de nombres desconocidos y de misiones tiende a desanimar al lector no informado sobre Sudamérica. Le sigue un capítulo extenso sobre la excursión de Miller a una estancia argentina, cuyo dueño es un inglés y donde conoce y describe a los famosos gauchos. El grueso del volumen se centra en la expedición al Perú, en los muchos incidentes en los que Miller participó y en las numerosas heridas graves que sufrió, y termina con la salida de San Martín del país.

El segundo volumen principia con un relato extenso de casi 90 páginas sobre las escaramuzas en las que Miller tomó parte a lo largo de la costa peruana. Luego, el centro de interés se desplaza a Bolívar y las batallas de Junín y Ayacucho. $\mathrm{Cu}-$ riosamente, se conservan las cartas de Miller en las que al referirse a esos acontecimientos sus relatos son más vividos 
que los de las Memorias. Después de la victoria de Ayacucho, el autor inserta unas cien páginas dedicadas a Cuzco y Potosí, y usa los datos recabados cuando fue gobernador ahí. En la segunda edición, incluye vasta información sobre Lima. A la descripción de la gran bienvenida a Bolívar en Potosí, organizada por Miller, añade una biografía extensa del Libertador, extraída del material que le proporcionó el general Sucre, que incluye las etapas venezolanas y colombianas de la vida de Bolívar y las batallas en las que combatió. Le sigue una exposición de reproches al Libertador y la Constitución bolivariana. El libro concluye con el retorno de Miller por tierra a Buenos Aires y su bienvenida en Salta.

Antes de entrar en el debate sobre San Martín y Bolívar, esbozo en términos generales la perspectiva de Miller. Era, por supuesto, protestante; un inglés liberal que adoptó o compartió el desdén de muchos de los liberales españoles y criollos hacia los efectos funestos del gobierno español en América y no se abstuvo de criticar la influencia del clero católico. Algunas de sus observaciones y burlas fueron discretamente eliminadas en la traducción castellana, pero su principal reproche contra el gobierno español era su fracaso en proveer una forma de gobierno propio. Como deja ver el prefacio de las Memorias, le complace alabar las buenas cualidades de los gauchos, huasos, cholos y montoneros, a quienes dirigió en sus varias capacidades como jefe en el Perú. Admite que eran feroces y crueles, pero también alaba su bravura y patriotismo. En cuanto a su crueldad, señala que se debía en parte a la reacción ante las represalias salvajes contra sus villorrios por parte de las fuerzas españolas. Al mismo tiempo, le sorprende la resistencia de las tropas nativas en los Andes y comenta que un batallón de 800 soldados marchaba 13 leguas por día, o sea unos 65 kilómetros, sin perder más de 15 hombres. Le causaba tal admiración el patriotismo y el carácter indomeñable de los gauchos, huasos y montoneros que advierte a sus compatriotas bri- 
San Martín y Bolívar: Los debates entre los legionarios ingleses e irlandeses sobre los méritos de los libertadores

tánicos que cualquier intento de conquistar esos países está destinado al fracaso. Miller subraya que una fuerza invasora podría quizá tener éxito en ocupar poblaciones, pero jamás en el campo, por lo anfractuoso del territorio sudamericano: quedaría aislada y expuesta a un ataque a mansalva. Tampoco le resultaba concebible la posibilidad de una monarquía en América y lamentaba la creación de ejércitos como una carga innecesaria sobre la hacienda pública. Lo que sorprende en todas sus reflexiones es la casi completa ausencia de condescendencia europea e imperial. Como militar, alaba a las tropas colombianas llevadas por Bolívar al Perú, las considera la mejor de las fuerzas que había visto, ya fuese en Europa o en América. Miller también realza la belleza de las mujeres de Santiago y Salta (y señala que varios de sus compatriotas se casaron con oriundas de esas ciudades).

Combinar los recuerdos personales con una historia militar general de las campañas de las guerras de la Independencia resultaba un tanto riesgoso como enfoque, porque pasaba por alto a muchos personajes, cuyos logros merecerían ser destacados y que podrían sentirse agraviados. Más aún, existía el riesgo de que el propio Miller se proyectara como alguien que había desempeñado un papel más importante del que tuvo en realidad, pues en ningún momento comandó grandes fuerzas en una operación independiente. Por todo ello, y por sus semblanzas de los dos libertadores y las opiniones sobre sus respectivas carreras, eran inevitables los comentarios desfavorables en América del Sur. Para entender ese sesgo, debemos recordar que Miller se asimiló al movimiento de la independencia en Chile y que debió sus promociones y ascensos a San Martín, hasta alcanzar el grado de general del ejército del Perú. Es verdad que alabó la calidad militar del ejército colombiano, pero grande fue su decepción al enterarse de que en el despacho oficial de la batalla de Ayacucho no se le había mencionado, cuando su participación en la ca- 
ballería había contribuido decididamente al resultado final. Mientras que los líderes colombianos fueron ascendidos a generales de división, Miller tuvo que esperar varios meses su reconocimiento. Más adelante, O'Connor observa que Sucre fue indebidamente parcial hacia sus compatriotas y descuidó dar a los oficiales peruanos el mérito de la promoción (Dunkerley, 1999).

A pesar de las reacciones irascibles de Wilson ante sus cartas, Miller ofrece en las Memorias una visión sobria de San Martín y lo critica por no llevar su fuerza expedicionaria a las regiones andinas, dado que Lima era una especie de trampa mortal para cualquier ejército. Asimismo, menciona que los planes de San Martín de establecer una monarquía en el país, enajenaron más que entusiasmaron a la élite peruana. En la primera edición de las Memorias, Miller finaliza el volumen con un retrato moderado de San Martín; sin embargo en la segunda, tanto en inglés como en español, le añade un párrafo donde lo compara con Washington. Esto es lo que escribe:

En el curso de estas Memorias se ha visto que a su genio creador pertenece la gloria de haber dado a las tropas la forma, organización, disciplina e instrucción debidas para marchar por un plan fijo militar hasta obtener la independencia de América del Sur; y que creando el hermoso ejército de los Andes, alcanzó con él enseguida la victoria en las alturas de Chacabuco y en los llanos de Maipú, y dio a Chile su existencia política. San Martín fue quien levantó el estandarte de la libertad en el Perú, y estableció en él las bases sólidas del gran plan terminado gloriosamente en Ayacucho. Cumpliendo San Martín con su promesa de dejar a los peruanos elegir su propia forma de gobierno, convocó un Congreso general constituyente, y luego de reunido se retiró de la vida pública, emulando el noble ejemplo de Washington, y con tal desinterés que las únicas riquezas que adquirió fueron los gloriosos y patrióticos hechos que ejecutó, en años y años de incesantes trabajos en el campo y en el bufete. (v. I, pp. 372-374). 
San Martín y Bolívar: Los debates entre los legionarios ingleses e irlandeses sobre los méritos de los libertadores

En cuanto a su sesgo político, le parece que San Martín consideró:

... la forma de gobierno monárquica constitucional la más adecuada para América del Sur, aunque sus principios son republicanos; pero es la opinión decidida de cuantos se hallaron en el caso de poderla formar correctamente que jamás tuvo la menor idea de colocar la corona en sus sienes, aunque se cree que habría ayudado gustoso a un príncipe de sangre real a subir al trono del Perú. (v. 2, 293-295).

El segundo volumen de las Memorias está dominado por la presencia de Bolívar, directa e indirectamente y ahí Miller adopta de forma deliberada una versión crítica del gran hombre. Lo que es todavía más importante, condena implícitamente la Constitución, señalándola como la creación impopular de una presidencia vitalicia. Afirma que el Libertador demostró ser mejor ante la adversidad que ante el triunfo, y que la adulación le hizo creer que sabía mejor que los peruanos mismos cómo convenía gobernar al Perú. Bolívar persuadió a los peruanos adoptar la Constitución bolivariana y elegirlo como su presidente; aspiraba gobernar de por vida una gran confederación de Colombia, Perú y Bolivia. Al mismo tiempo, Miller denuncia el Congreso de Panamá, pues afirma que lo único que logró fue emitir ciertas proclamas.

En suma, Miller, al extender su motivo de crítica de Bolívar en la segunda edición de sus Memorias, refleja el estado de ánimo del Perú contra el Libertador, a quien se vio con rechazo como conquistador y además extranjero. También señala que, en tales casos, no hay que esperar gratitud. Por otra parte, alaba al general José de la Mar, quien había asumido la presidencia una vez que el Perú rompió con Bolívar y su Constitución y aseguró la salida de las tropas colombianas del país. Para sostener sus argumentos, Miller incluyó en el apéndice de la obra la traducción de la Constitución bolivariana, notable por la grandilocuencia del discurso inaugural que el Libertador pronunció en Bolivia. 


\section{Aquí se reproduce la semblanza de Bolívar:}

El general Bolívar es delgado y algo menos que de regular estatura. Se viste bien y su forma de andar y presentarse es franca y militar. Como jinete es muy fuerte y atrevido, capaz de resistir grandes fatigas. Tiene buenos modales y un aire sin afectación, pero que no predispone mucho a su favor. Se dice que en su juventud fue atractivo, pero actualmente tiene el rostro pálido, pelo negro con canas y ojos negros y penetrantes, generalmente inclinados hacia abajo o de lado cuando habla; nariz bien formada, frente alta y ancha y barbilla afilada; la expresión de su semblante es cautelosa, triste y algunas veces de fiereza. Su carácter, viciado por la adulación, es arrogante y caprichoso. Sus opiniones respecto de los hombres y a las cosas son variables y tiene casi una propensión a insultar, pero favorece demasiado al que se le humilla, y con éstos no guarda ningún resentimiento. Es un apasionado del bello sexo, pero extremadamente celoso. Tiene afición a valsar y es muy ligero, pero no baila con gracia. Su imaginación y su persona son de una actividad extraordinaria; cuando no se halla en movimiento, está siempre leyendo, dictando cartas, etc., o hablando. Su voz es gruesa y áspera, pero habla con elocuencia de casi cualquier tema. Su lectura la ha dedicado casi exclusivamente a autores franceses y de ella provienen los galicismos que tanto emplea en sus textos; escribe de un modo que causa impresión, pero su estilo está viciado por una afectación de grandeza que desagrada. Hablando tan bien y fácilmente como lo hace, no es de extrañar que prefiera escucharse a sí mismo que oír a los demás, y que acapare la conversación cuando recibe visitas. Da grandes convites, y no hay nadie que tenga cocineros más hábiles que él, ni que dé mejores comidas; pero es tan parco en comer y beber que rara vez ocupa su lugar en su propia mesa hasta que casi se ha acabado de comer, habiendo comido antes probablemente en privado uno o dos platos sencillos. Es muy aficionado a hacer brindis, los cuales anuncia del modo más elocuente y adecuado; y es tan grande su entusiasmo que frecuentemente se sube en la silla o la mesa para proponerlos. Aunque el cigarro es de uso universal en la América del Sur, Bolívar no fuma y no permite fumar en su presencia. Nunca está ni se presenta sin la comitiva correspondiente y guarda una gran etiqueta, y aunque desinteresado en extremo en lo 
San Martín y Bolívar: Los debates entre los legionarios ingleses e irlandeses sobre los méritos de los libertadores

concerniente a asuntos pecuniarios, es insaciablemente codicioso de gloria. (v. 2, pp. 293-295)

A pesar de su crítica a las Memorias de Miller, Wilson siguió, como se mencionó, relativamente en buenos términos con el autor. En los años treinta, sus posiciones se invirtieron: Wilson representaba a la Gran Bretaña como chargéd'affaires y desempeñaba un papel central de apoyo a la Confederación Peruano-Boliviana formada por Andrés de Santa Cruz. En contraste, Miller continuaba su rol militar en la compleja política de ese periodo. No fue hasta los cincuenta cuando Wilson reanudó su correspondencia con Miller. Para entonces, se había jubilado tras su periodo como chargéd'affaires de su majestad en Venezuela; en reconocimiento de sus méritos recibió la alta condecoración de Caballero de la Orden del Baño.

El tono de sus cartas en esa etapa de su vida es más petulante que partidario, aunque exaltado en cuanto a la ineficiencia del gobierno de la Gran Bretaña en su conducción de la guerra de Crimea. Sin embargo, Wilson más bien se remitía a los sucesos de su juventud y sus casi dos décadas de experiencia como representante diplomático en Lima y Caracas. Es entonces cuando rinde homenaje a Miller como libertador y alcanza un equilibrio en el juicio sobre la carrera de Bolívar $y$, por cierto, señala atinadamente la distancia sudamericana. En ese sentido, se muestra implícitamente de acuerdo con la crítica de Miller sobre la Constitución y los intentos de

258 imponerla en el Perú y en Colombia.

Escribe lo siguiente:

Salvo en Chile, la situación de la América del Sur es satisfactoria, pese al deplorable manejo de la administración. Mi opinión es que las poblaciones son más prósperas y más felices que de haber continuado como colonias españolas. La verdad es que la situación de España no es mejor que la de 
Sudamérica, ni política, ni social, ni moralmente. Ustedes los libertadores, por lo tanto, no tienen nada que reprocharse. Hablando de libertadores, desafortunadamente, ni tú comprendiste correctamente los verdaderos méritos y servicios del Libertador, ni él los tuyos. Ambos se encerraron demasiado en los errores y las debilidades del otro. Y por lo tanto nunca se hicieron justicia el uno al otro. Eso no importa, porque los dos han ganado su lugar en la historia de la América del Sur y ambos serán debidamente reconocidos. A pesar de las flaquezas de la condición humana, el general Bolívar fue un gran hombre y su nombre figurará por siempre en los anales de la grandeza humana, pues aprovechó al máximo sus talentos personales. Su genio, sus dotes especiales, eran su independencia de carácter y su determinación, los cuales le sirvieron para perseguir sus convicciones de lograr la independencia de la América del Sur como parte de los ideales más amplios de la civilización y la humanidad. Con recursos limitados y escaso apoyo, él alcanzó lo que muchos otros mejor dotados no consiguieron. Bolívar no tuvo vocación política o administrativa, por eso fracasó. No obstante, obtuvo la independencia y la libertad de su país, su conquista más grande y su reivindicación de la fama. Sus lucubraciones políticas son objeto de opinión de la historia, pero por lo menos eran convicciones honestas. San Martín fue, en mi opinión, un patriota honrado y un hombre distinguido, pero no fue un "gran hombre" en la acepción usual de ese término. Tenía pocas de las características del genio; Sucre estaba mejor dotado, pero la palma por sus servicios debe ser otorgada a San Martín por sobre Sucre, pese a su gran y gloriosa victoria. Sucre fue sin embargo un administrador político capaz y honesto, y hubiese sido un admirable presidente de la República. (Wilson a Miller, Buxton, 24 de noviembre de 1856)

5 Belford Hinton Wilson Papers. The John Carter Brown Library. 
San Martín y Bolívar: Los debates entre los legionarios ingleses e irlandeses sobre los méritos de los libertadores

\section{Conclusiones}

Para mostrar cómo el debate entre Miller y Wilson se expresó primero, y en parte influyó después en la polémica en la América española en cuanto a los méritos respectivos de San Martín y Bolívar, retornemos a la furiosa carta de Wilson a Miller del año 1833: "Los documentos refutarán todas tus recientes acusaciones. Sé que existen; no fue la intención de O'Leary atacarte, pero tú lo obligaste a defender el honor del Libertador y el suyo personal, y lo hará publicando los hechos" (Carta de Wilson a Miller, Callao, 23 de octubre de 1833). Tal como afirma Wilson, O'Leary, heredero de los documentos de Bolívar, seguía haciendo acopio de materiales que publicaría su hijo en los ochenta. En sus memorias, escritas a principios de la década de los cuarenta, O'Leary no menciona las cartas de Miller, aun cuando en dos ocasiones cita cartas de Wilson. La intención del edecán irlandés no era solo presentar a Bolívar como héroe y genio, sino también refutar la crítica de Miller. En su elogio ilimitado del Libertador, O'Leary alude al calificativo que Miller les había adjudicado a él y a Wilson como "los agitadores" de la causa.

Las semblanzas y los comentarios escritos por estos súbditos británicos, fuesen ingleses o irlandeses, reflejan y expresan las opiniones y los prejuicios de los generales, ideólogos y políticos hispanoamericanos de la época de la independencia. En ese sentido, hay que reconocer su papel en los albores de una controversia que se mantiene viva hasta nuestros días: la comparación y los contrastes entre la figura y la obra de los dos grandes libertadores.

Recibido:12 de noviembre del 2020

Aprobado: 10 de abril del 2021 


\section{Referencias bibliográficas}

Bolívar, S.

(1950) Obras completas (3 v.). Compiladas por Vicente Lecuna con la colaboración Esther Barret de Nazaris. La Habana. I, 223.

Brading, David A.

(1987) Heroes Republicanos y Tiranos Populares. Mexico Cauadernos Americanos Nueva Epoca No 11 Septiembre-Octubre. Vol 5.

Denegri Luna, F.

(1955) Un Auto de Fe en el Cuzco de 1835. Tradición (1920), 25-30.

Dunkerley, J.

(1999) The Third Man: Francisco Burdett O'Connor and the Emancipation of the Americas. London: Institute of Latin American Studies.

Miller, J.

(1929) Memorias del General Miller al servicio de la República del Perú, escritas en inglés... y traducidas al castellano por el General Torrijos, amigo de ambos (2. v). Londres: Longman, Rees, Orme, Brown y Green.

Mitre, B.

(1950) Historia de San Martín y de la emancipación sudamericana. Buenos Aires: El Ateneo.

O'Connor, B. F.

Independencia Americana. Recuerdos de Francisco Burdett O'Connor, Coronel de Ejército Libertador de Colombia y General de División de los de Perú y Bolivia. Ed. América. Biblioteca Ayacucho.

O'Leary, D.

Bolivar y la emancipación de Sur-América. Memorias del general O'Leary traducidas del inglés por su hijo Simón O'Leary, 1819-1826. Madrid: Biblioteca Ayacucho. 
San Martín y Bolívar: Los debates entre los legionarios ingleses e irlandeses sobre los méritos de los libertadores

O'Leary, D. F.

(1888) Memorias del General O'Leary. Publicadas por su hijo Simón B. O’Leary. Caracas: Imp. de la Gaceta Oficial. $31 \mathrm{v}$.

O'Leary, D. F.

(1920) Correspondencia de extranjeros notables con el Libertador. Madrid: Ed. América.

Wu Brading, C.

(1993) Generales y diplomáticos. Gran Bretaña y el Perú 18201840. Lima, Fondo Editorial Pontificia Universidad Católica del Perú.

Wu Brading, C.

(2004) Sir Belford Hinton Wilson, 1804-1858. En Oxford dictionary of national biography. Oxford University Press.

Wu Brading, C.

(2007) Liberator and Historian, 1795-1861. The ceremony of the unveiling of the memorial of William Miller at St. Mary the Virgin Church in Wingham, Canterbury.

Wu Brading, C.

(2019) Epílogo. En S. O’Phelan, M. Novoa y M. Laguerre, Miller, militar, político y peruanista, 1795-1861. Lima: Asociación Cultural Peruano-Británica. 